\title{
Distinctive vasculopathy with systemic involvement due to levamisole long-term therapy: a case report
}

\author{
Bilal Aoun', Mohammad Alali ${ }^{2}$, Jad A. Degheili ${ }^{3}$, Sami Sanjad ${ }^{1}$, Claudine Vaquin ${ }^{4}$, Jean Donadieu ${ }^{5}$, Tim Ulinski ${ }^{6}$ \\ and Salah Termos ${ }^{2^{*}}$
}

\begin{abstract}
Background: Levamisole belongs to the antihelminthic class of drugs that are sometimes administered to patients with frequently relapsing or steroid-dependent nephrotic syndrome, owing to its steroid-sparing effects. Neutropenia and skin lesions, compatible with vasculitis, have been reported as drug complications, but they are rarely associated with any systemic involvement.

Case presentation: We report a case of a 9-year-old Arab boy with steroid-dependent nephrotic syndrome who was treated with levamisole after his third relapse. The drug was initially well tolerated, but mild isolated neutropenia occurred 6 months after levamisole administration. This was followed by cutaneous vasculitis of both ears and the left cheek. The patient also developed hepatosplenomegaly and anemia. Levamisole was discontinued, and his disease remained in remission. All the systemic manifestations disappeared gradually over the course of 1 month. The patient remained in remission until 1 year after levamisole withdrawal, when clinical nephrosis recurred.

Conclusions: Despite levamisole's being a useful drug for maintaining remission in steroid-dependent nephrotic syndrome, patients on long-term levamisole therapy should be monitored closely to prevent serious complications that can easily be resolved by simple drug withdrawal.
\end{abstract}

Keywords: Levamisole, Nephrotic syndrome, Cutaneous vasculitis, Neutropenia, Hepatosplenomegaly

\section{Background}

Levamisole-induced vasculitis is a characteristic cutaneous vasculitic syndrome usually associated with levamisole-adulterated cocaine intake and rarely with the use of levamisole for refractory treatment of nephrotic syndrome [1]. Patients typically present with a painful purpuric rash in a retiform or stellate pattern, with or without central necrosis, involving both extremities, the trunk, nasal tip, digits, cheeks, and ears. Laboratory workup findings may include leukopenia, neutropenia, and positive autoantibodies, mainly antineutrophil cytoplasmic antibodies (ANCAs) [2, 3]. A literature review revealed only a few cases of levamisole-induced vasculitis during treatment of steroid-sensitive and steroid-resistant nephrotic

\footnotetext{
* Correspondence: dr.termos@hotmail.com

${ }^{2}$ Hepatobiliary and Transplant Unit, Department of Surgery, Al-Amiri Hospital, Kuwait City, Kuwait

Full list of author information is available at the end of the article
}

syndrome. The majority of those patients were in the pediatric age group, and their clinical presentation was rarely associated with systemic complications such as persistent neutropenia, hepatosplenomegaly (HSM), and anemia [4]. In this report we describe a distinctive vasculopathy with systemic involvement in a child with steroid-dependent nephrotic syndrome (SDNS) who received long-term levamisole therapy. Complete resolution occurred after drug withdrawal.

\section{Case presentation}

Our patient was a 9-year-old Arab boy who had had SDNS since the age of 5 years. Because of several relapses over the previous 4 years, and in an effort to spare steroid use and its long-term use complications, the patient was treated with levamisole. His family history revealed that his parents are nonconsanguineous and his father works as a taxi driver. Levamisole was initially well tolerated 
except for mild isolated and persistent neutropenia (absolute neutrophil count of $1400 \mathrm{cell} / \mathrm{mm}^{3}$ ), which had occurred 6 months after levamisole introduction. The patient had no history of cocaine exposure. Viral infections were ruled out (cytomegalovirus, Epstein-Barr virus, and parvovirus B19). Because the patient's neutrophil count remained stable and he was in sustained remission, levamisole was maintained at the same dosage $(2.5 \mathrm{mg} / \mathrm{kg}$ every other day). Six months later, he developed nonspecific lichenoid eruptions on both ears and the left cheek, compatible with cutaneous vasculitis [Fig. 1]. Upon a physical examination, the patient was found to be alert, with vital signs of blood pressure 100/50 $\mathrm{mmHg}$ and body temperature $36.7{ }^{\circ} \mathrm{C}$. His heart sounds were regular and rhythmic with a heart rate of 80 beats $/ \mathrm{min}$. The result of a neurological examination including sensory and motor responses, especially reflexes, was normal. The boy's lungs were clear and resonant. His liver and spleen were moderately enlarged. He had lichenoid eruptions on both ears and his left cheek. Ultrasound of the abdomen revealed HSM with liver and spleen lengths of $14 \mathrm{~cm}$ and $13 \mathrm{~cm}$, respectively. Mild anemia (hemoglobin $9.7 \mathrm{~g} / \mathrm{dl}$ ) was detected 3 months prior to the appearance of skin lesions. The patient's kidney function was normal with a creatinine level of $60 \mu \mathrm{mol} / \mathrm{L}$. Liver function tests reflected by aspartate aminotransferase and alanine aminotransferase showed slightly elevated levels of $120 \mathrm{IU} / \mathrm{L}$ (normal range 5-60 IU/L) and $50 \mathrm{IU} / \mathrm{L}$ (normal range 7-40 IU/L), respectively, and a normal alkaline phosphatase level of $60 \mathrm{IU} / \mathrm{L}$.

Immunological investigation revealed an increased positive ANCA count of $>1 / 640$, with negative antinuclear antibodies. Serum complement levels (C3, C4, and $\mathrm{CH} 50$ ) were normal. At this point, levamisole was discontinued. He remained in remission, and his skin lesions disappeared 1 week later. His neutrophil count and hemoglobin levels normalized concomitantly. Furthermore, HSM decreased within 1 month following the withdrawal of levamisole, with liver and spleen lengths becoming $11 \mathrm{~cm}$ and $8 \mathrm{~cm}$, respectively. His ANCA levels, however, remained positive $(>1: 640)$ for 12 months after drug cessation. Six months after levamisole withdrawal, the patient remained in remission, with normal white and red blood cell counts and absence of HSM (Fig. 2). One year after levamisole withdrawal, the patient started to develop frequent relapses requiring the combination of steroids and mycophenolate mofetil (MMF) to ensure remission. The patient was never hospitalized and had ambulatory management. Our patient's clinical course is illustrated in Fig. 2, denoting the relationship between levamisole use, discontinuation, and its marked effect on the neutrophil/hemoglobin levels.

\section{Discussion}

Levamisole was originally marketed as an antihelminthic agent, but it was also found to have major immunomodulatory properties. It induces interferon synthesis and synergizes the effect of steroids and other immunosuppressants. It was used in cancer therapy to treat various immunological renal diseases and skin diseases such as Behçet's disease. However, the drug was withdrawn from the market in 1999 because of serious side effects, including leukopenia, agranulocytosis, and skin vasculitis [5]. It is still available as a veterinary deworming drug and for treatment of refractory nephrotic syndrome.

Children with SDNS may require several immunosuppressive drugs to control their disease. Such drugs include cyclosporine, cyclophosphamide (CYC), MMF, and

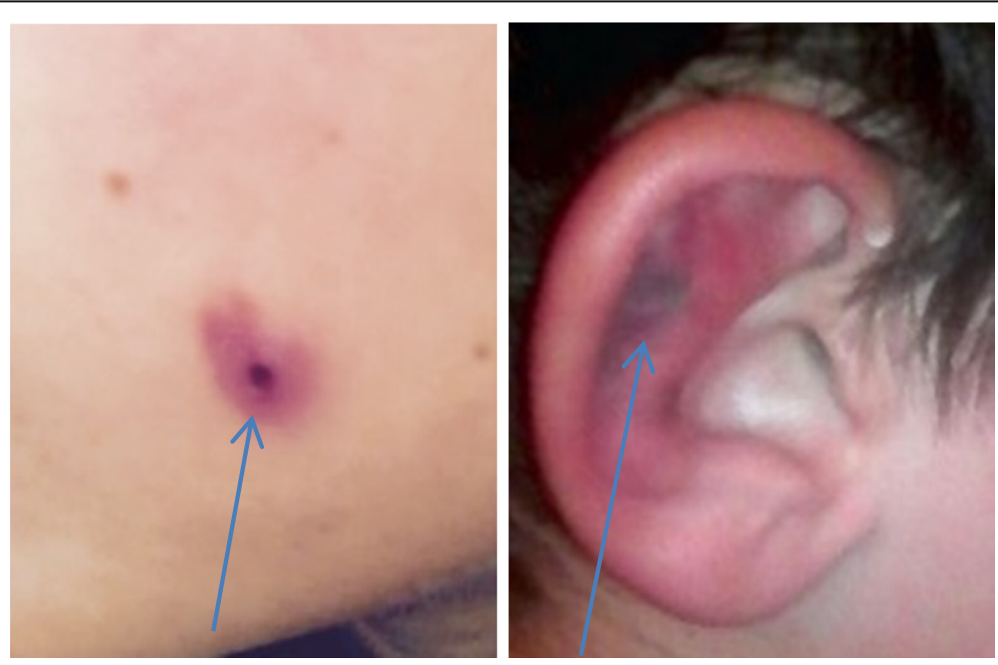

Fig. 1 Skin lesions (arrows) present on left cheek and ear pinna, characterized by central necrosis 


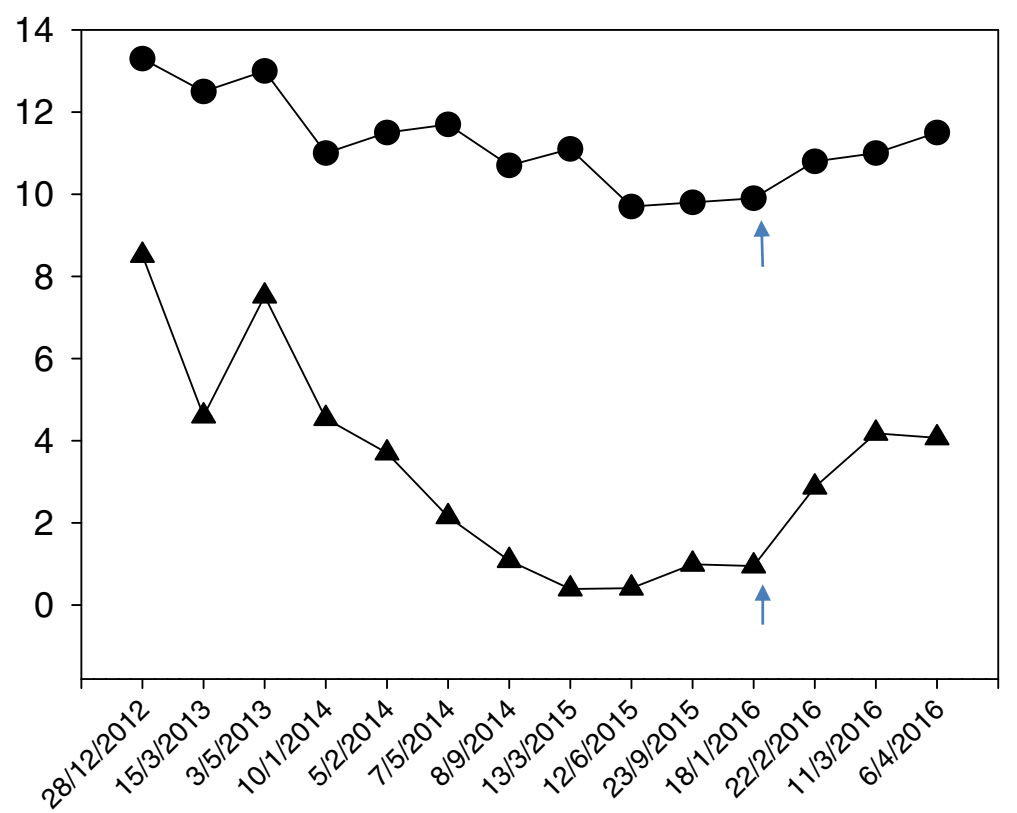

Fig. 2 Schematic graph indicating the variations in hemoglobin ( $\mathrm{Hgb}$ ) and neutrophil level (arrows) during period of levamisole administration and withdrawal, along the treatment course. The dotted line denotes the Hgb value, and the arrowhead line represents the neutrophil count

levamisole. CYC and MMF have been shown to display long-term efficacy in SDNS [6-8]. As reported previously, levamisole has been considered the least toxic and the least expensive steroid-sparing drug for prevention of relapses in SDNS [9].

Although the exact mechanism of levamisole action in maintaining remission in patients with idiopathic nephrotic syndrome (INS) is still unknown, it is postulated that the drug enhances the Th1-mediated immune response and reciprocally downregulates the Th2 lymphocyte-mediated immune response. Recently, it was suggested that levamisole's mode of action is attributable to its direct effects on podocytes [10]. On the contrary, the mechanism proposed for drug-induced neutropenia seems to be secondary to antibody formation and autoantibody production, against drug metabolites or protein adducts, covalently attached to neutrophil membrane proteins [11].

INS is a rare disease with an incidence of 2-7 per 100,000 children. It is the most common cause of nephrotic syndrome in the pediatric population [12]. Glucocorticoids remain the treatment of choice in INS to induce remission. However, the disease relapse rate is up to $80 \%$, and many patients may become steroid-dependent in the long term [13] and may require other immunosuppressive agents to maintain remission and limit the corticosteroid's dosage.

In a study by Bagga et al. [14] with 43 children with INS, no significant side effects were experienced; thus, none of the subjects required withdrawal of levamisole. In a case series by Barbano et al. [15], a child with INS and prolonged levamisole treatment developed cutaneous vasculitis and HSM, requiring medication withdrawal.

What is unique to our patient is the side effects that he experienced after 6 months of levamisole treatment. Thus, despite levamisole's being reported as a safe drug, our patient showed that even after a relatively short course of levamisole administration, severe side effects may occur, necessitating its withdrawal.

\section{Conclusions}

Levamisole-induced cutaneous vasculitis with systemic involvement in patients with nephrotic syndrome is a rare complication of a relatively rare disease. Despite its being a useful drug for maintaining remission in patients with SDNS, those maintained on long-term levamisole therapy should be monitored closely, both clinically and by laboratory workup, to detect early abnormalities and prevent serious complications that can be resolved by drug withdrawal.

\section{Availability of data and materials}

All data and materials related to this report are accessible at any time upon request.

\section{Authors' contributions}

$B A, T U, C V$ and SS followed the patient clinically. BA and JD wrote the case report. MA and JAD helped in literature review. ST and SS revised the article and did literature review, as well. MA performed the data collection. All authors read and approved the final manuscript.

Ethics approval and consent to participate Not applicable. 


\section{Consent for publication}

Written informed consent was obtained from the patient's legal guardian(s) for publication of this case report and any accompanying images. A copy of the written consent is available for review by the Editor-in-Chief

of this journal.

\section{Competing interests}

The authors declare that they have no competing interests.

\section{Publisher's Note}

Springer Nature remains neutral with regard to jurisdictional claims in published maps and institutional affiliations.

\section{Author details}

'Division of Pediatric Nephrology, Department of Pediatrics, American University of Beirut, Beirut, Lebanon. ${ }^{2}$ Hepatobiliary and Transplant Unit, Department of Surgery, Al-Amiri Hospital, Kuwait City, Kuwait. ${ }^{3}$ Division of Urology, Department of Surgery, American University of Beirut Medical Center, Beirut, Lebanon. ${ }^{4}$ Division of Pediatric Dermatology, Armand Trousseau Hospital, Assistance Publique - Hôpitaux de Paris (AP-HP), Paris, France. ${ }^{5}$ Division of Pediatric Hematology, Armand Trousseau hospital (APHP), Paris, France. ${ }^{6}$ Division of Pediatric Nephrology, Armand Trousseau Hospital, Assistance Publique - Hôpitaux de Paris (APHP), Paris, France.

Received: 22 January 2018 Accepted: 28 May 2018

Published online: 16 July 2018

\section{References}

1. Tran H, Tan D, Marnejon TP. Cutaneous vasculopathy associated with levamisoleadulterated cocaine. Clin Med Res. 2013;11(1):26-30. PMID: 22723468

2. Álvarez Díaz H, Marińo Callejo Al, García Rodríguez JF, Rodríguez Pazos L, Gómez Buela I, Bermejo Barrera AM. ANCA-positive vasculitis induced by levamisole-adulterated cocaine and nephrotic syndrome: the kidney as an unusual target. Am J Case Rep. 2013;14:557-61. PMID: 24478818

3. Pearson T, Bremmer M, Cohen J, Driscoll M. Vasculopathy related to cocaine adulterated with levamisole: a review of the literature. Dermatol Online J. 2012;18(7):1. PMID: 22863623

4. Tenbrock K, Müller-Berghaus J, Fuchshuber A, Michalk D, Querfeld U. Levamisole treatment in steroid-sensitive and steroid-resistant nephrotic syndrome. Pediatr Nephrol. 1998;12(6):459-62. PMID: 9745868

5. Chang A, Osterloh J, Thomas J. Levamisole: a dangerous new cocaine adulterant. Clin Pharmacol Ther. 2010;88(3):408-11. PMID: 20668440

6. Bircan Z, Kara B. Intravenous cyclophosphamide is the drug of choice for steroid dependent nephrotic syndrome. Pediatr Int. 2003;45(1):65-7. PMID: 12654072

7. Bagga A, Hari P, Moudgil A, Jordan SC. Mycophenolate mofetil and prednisolone therapy in children with steroid-dependent nephrotic syndrome. Am J Kidney Dis. 2003:42(6):1114-20. PMID: 14655181

8. Mendizábal S, Zamora I, Berbel O, Sanahuja MJ, Fuentes J, Simon J. Mycophenolate mofetil in steroid/cyclosporine-dependent/resistant nephrotic syndrome. Pediatr Nephrol. 2005;20(7):914-9. PMID: 15891923

9. Abeyagunawardena AS, Karunadasa U, Jayaweera $H$, Thalgahagoda S, Tennakoon S, Abeyagunawardena S. Efficacy of higher-dose levamisole in maintaining remission in steroid-dependent nephrotic syndrome. Pediatr Nephrol. 2017:32(8):1363-7. PMID: 28299461

10. Jiang L, Dasgupta I, Hurcombe JA, Colyer HF, Mathieson PW, Welsh Gl. Levamisole in steroid-sensitive nephrotic syndrome: usefulness in adult patients and laboratory insights into mechanisms of action via direct action on the kidney podocyte. Clin Sci (Lond). 2015;128(12):883-93. PMID: 25626449

11. Curtis BR. Drug-induced immune neutropenia/agranulocytosis. Immunohematology. 2014;30(2):95-101. PMID: 25247619

12. Deschênes $G$, Leclerc $A$. Epidemiology of the idiopathic nephrotic syndrome. Arch Pediatr. 2010;17(6):622-3. PMID: 20654810

13. Gipson DS, Massengill SF, Yao L, et al. Management of childhood onset nephrotic syndrome. Pediatrics. 2009;124(2):747-57. PMID: 19651590

14. Bagga A, Sharma A, Srivastava RN. Levamisole therapy in corticosteroiddependent nephrotic syndrome. Pediatr Nephrol. 1997;11(4):415-7. PMID: 9260236

15. Barbano G, Ginevri F, Ghiggeri GM, Gusmano R. Disseminated autoimmune disease during levamisole treatment of nephrotic syndrome. Pediatr Nephrol. 1999;13(7):602-3. PMID: 10460511

\section{Ready to submit your research? Choose BMC and benefit from:}

- fast, convenient online submission

- thorough peer review by experienced researchers in your field

- rapid publication on acceptance

- support for research data, including large and complex data types

- gold Open Access which fosters wider collaboration and increased citations

- maximum visibility for your research: over $100 \mathrm{M}$ website views per year

At BMC, research is always in progress.

Learn more biomedcentral.com/submissions 